\title{
ALÉM DAS PALAVRAS DE GAUTAMA
}

Fernando Carlos Chamas

RESUMO: Devido à sua complexidade, para se pesquisar a Escultura Budista Japonesa, necessita-se de uma metodologia cientificamente capaz de levantar elementos que a autentiquem enquanto arte. Através de qualquer estátua budista, seja ela simples como a imagem do "buda gordo" seja pelas obras-primas dos templos budistas japoneses, almejamos neste artigo tecer uma trama de referências iconográficas, históricas e lendárias cuja extensão ultrapassa os limites das convenções artísticas ocidentais, a restrição dos recortes metodológicos e a própria geografia.

ABSTRACT: The research of the Japanese Buddhist Sculpture, due to its complexity, demands a methodology scientifically able to sort out principles which could legitimize it as art. Through any Buddhist statue, even a simple one like "fat buddha" or Japanese buddhist temples masterpieces, it is aimed in this article to relate a web of iconographic, historical and legendary references whose extension exceeds the limits of western artistic conventions, the restriction imposed by methodological cutting outs and the asiatic geographical frontiers.

PALAVRAS-CHAVE: budismo, escultura, Japão, realismo.

KEYWORDS: buddhism, sculpture, Japan, realism.

Uma das religiões mais antigas do mundo é também uma das mais presentes na Cultura Japonesa, mas pouco se fala sobre a escultura budista daquele país. Essa foi produzida em grande quantidade por pelo menos dez séculos consecutivos desde a introdução do budismo no Japão. Há livros japoneses sobre esse assunto, já traduzidos 
em outras línguas, mas, no Brasil, não há uma tradução ou pesquisa sobre o mesmo. Em busca da metodologia para pesquisar as imagens budistas, poderemos notar que o campo é extremamente vasto em pormenores, não só pela filosofia religiosa do budismo, mas também pela extensão de sua arte, no tempo e no espaço, fora e dentro do Japão.

A imagem a que chamam de Buda (em japonês, hotoke ou butsu, 仏), no Brasil, denota uma popularidade banal, do tipo que pode ser encontrada em objetos de sorte e decoração. Comumente, há muitas estatuetas budistas em lojas indianas, esotéricas ou new age, sendo que a imagem mais conhecida é a de um Buda gordo na posição sentada e com expressão sorridente.

Uma breve biografia de Sidharta Gautama, mesmo pelos que não se interessam pelo budismo, é suficiente para deduzir que, fisicamente, Buda não poderia ser gordo e não foi da etnia japonesa. Então, para aqueles que se aprofundam, paira uma dúvida.

A resposta mais fácil seria dizer que o Buda gordo é um d"Os Sete Deuses da Sorte ou da Felicidade" (em japonês, Shichifukujin, 七福神), conhecido no Japão como Hotei (布袋).

Hotei é o nome japonês para um monge zen chinês chamado Pu-tai que viveu no final da dinastia Tang ou das Cinco Dinastias (907 960), nascido em Feng-hua-xian, Ming-zhou. Dizem que Hotei andava ao redor da cidade com a barriga exposta e um bastão em seu ombro com um saco de cânhamo (hotei) para esmolas. Essa imagem se espalhou no Ocidente como sendo a do buda Sakyamuni, o buda do clã Sakya (ex-príncipe Sidharta Gautama, nascido em Lumbini, perto da cidade de Kapilavastu, hoje Tilonakot, no Nepal Meridional, Índia). A imagem de Hotei às vezes está rodeada de crianças e se acredita que esfregar a sua grande barriga e oferecer moedas traz sorte ou que colocá-lo de costas para a porta principal impede a entrada de males.

Para dar outra resposta, precisamos mergulhar em um universo budista que não foi inventado por Gautama. Esse universo é representado como uma montanha, Monte Sumeru, ou uma Mandala (um "planta" do cosmos), com milhares de seres, em diferentes graus de "iluminação" ("emancipar-se do mundo material") em diferentes mundos. Portanto, há muitas imagens, em pinturas e esculturas, e a explicação de todas elas seria o trabalho de uma vida inteira e mesmo assim nunca seria completa.

Buda era esperado, assim como outros "salvadores" em outras religiões. Segundo a lenda, quando um velho profeta visitou o bebê buda, viu nele marcas de um grande príncipe ou um grande asceta, ou seja, já existia uma crença ancestral nos budas. Acredita-se que Gautama foi o sétimo buda "de nossa era" No Japão, Hotei também é tido como uma encarnação de outro buda chamado Miroku, que "agora" está em outro mundo, preparando-se para ser o oitavo buda do planeta Terra. Miroku é um bosatsu, (categoria explicada adiante), classe de seres que ainda não passaram pelo nirvana (em japonês, nehan, 涅槃), palavra sânscrita que significa "morte de uma pessoa santa e libertação do ciclo de reencarnações"

Além disso, o fato de Hotei ser gordo e ser considerado "protetor dos lares" tem semelhança com o deus hindu Ganesha, com cabeça de elefante e um grande ventre. Uma barriga exposta, grande ou pequena, mas nunca magra, tem sido um índice 
importante em grande parte das imagens budistas. Sabedoria, compaixão e sensualidade não são qualidades dissociadas, e na barriga, concentram-se expressão de saúde, vistosidade, elegância e fertilidade.

Ganesha, o elefante, sobretudo branco, é um símbolo importante na Índia e, no Brasil, é tomado como símbolo de sorte e proteção. Quando grávida, a mãe de Buda sonhou com um elefante branco. Estar grávida de um deus é estar grávida da própria sabedoria, e um grande ventre simboliza a sabedoria infinita de seu possuidor. Buda, na coletânea de contos sobre suas vidas passadas, Jataka (em japonês, Honjôtan 本生 譚), já foi um elefante. Como os elefantes, algumas imagens de Hotei também são encontradas em porcelana branca. A escolha do material para essas esculturas tornou-se fator importante para sua expressão. É interessante notar que esse tipo de objeto - que parece a alguns apenas como decoração é chamado de esotérico. Há um conhecimento intuitivo dessa palavra que foi disseminada como uma arte de caráter místico relacionada a elementos naturais. Pode ser a imagem de um buda sorridente ou em meditação, ou apenas a sua cabeça com face plácida, de superfície branca ou dourada, em porcelana, pedra ou madeira nua ou pintada. As esculturas em madeira polida, com os veios à mostra e aparência suave, foram características apreciadas na escultura budista japonesa.

Por fim, Hotei também está ao lado de deuses celestiais (em japonês, tenbu, 天 部), originariamente deuses do hinduísmo incorporados ao budismo como protetores "belicosos" Portanto, Hotei também faz parte das "Divindades Guardiãs" conhecidas no Japão como as 28 Legiões de Divindades Guardiãs (em japonês, Nijûhachibushû, 二十八部衆).

Essa necessidade de possuir um "exército de divindades" para proteger os budistas e as suas escrituras (os sutras) é uma das principais características do "budismo oculto" ou esotérico (em japonês, mikkyô, 密教). Cada divindade budista possui a sua mitologia mais ou menos clara, assemelhando-se a alguma mitologia hindu modificada durante a longa viagem ao Japão. Em geral, não podemos ignorar que todas as imagens devem ter sofrido diferentes graus de modificação em características físicas secundárias, recebendo ou perdendo significados conforme os interesses de uma determinada cultura.

Aos poucos, as informações vão formando uma trama e não é estranha a relação com o budismo "da trama" ou tântrico" Quanto mais nos aprofundamos, mais

1. Esse movimento é uma forma esotérica do budismo mahayana, que foi difundido para o Japão como Mikkyô, ensinamentos secretos ou esotéricos para a transformação da mente. Também se pode considerá-la uma terceira escola junto com o budismo hinayana. Mahayanismo e Hinayanismo são as duas principais correntes do budismo. Respectivamente significam "Grande Veículo" e "Pequeno Veículo", Daijô Bukkyô (大乗仏教) e Shôjô Bukkyô (小乗仏教) em japonês. A escola vajrayana chinesa foi fundada no século VII pelos indianos Shuvhakarasimha (637 735), Vajrabodhi (663 723) e Amoghavajra (705 774). Vajrayana é o "Veículo Diamante" ou Tantrayana (Veículo dos Tantras) ou Mantrayana (Veículo do Mantra), que surgiu por volta do século V nas regiões nordeste e noroeste da Índia. Vajrayana é a corrente "esquerda" do tantrismo, a contraparte feminina das divindades budistas. Mantrayana é a corrente "direita" e sobrevive na escola Shingon, que enfatiza o gesto das mãos. Também é praticado no Nepal, Mongólia, Tibete e Butão. "O Tantra se baseia na recitação de encantamentos, na realização de gestos e danças rituais e uma 
caminhamos em direção à ancestralidade de uma região entre o Oriente Médio e o Norte da Índia, em direção ao hinduísmo, a religião nativa da Índia, nascida a partir de uma miscelânea de crenças populares e pela sua escritura mais antiga, Os Vedas ${ }^{2}$ Assim, o tantrismo, o hinduísmo, as divindades bosatsu, tenbu e outras, com as influências do taoísmo e do confucionismo ${ }^{3}$ caracterizam o budismo esotérico que entrou no Japão, quando então recebeu influências do xintoísmo, a religião nativa japonesa. Complexo, o budismo esotérico é conhecimento difícil de ser apreendido, a não ser por iniciados que dedicam suas vidas ao seu entendimento mais pela intuição do que pelo raciocínio, processo que se estende às imagens. Gautama teria originado o "budismo revelado" ou exotérico (em japonês, kenkyô, 顕教), ensinando sem misticismo o caminho da iluminação, mas o esoterismo afirma que parte do conhecimento transmitido por Gautama só pode ser compreendido por exercícios místicos, como a recitação dos mantras (versos místicos) e a posição do corpo e das mãos, com os quais se acredita atingir níveis suprarracionais de compreensão. Esses gestos e posturas estão eminentemente presentes na escultura budista.

Assim sendo, esse estudo envolve uma área geográfica e um período de tempo muito extenso, além do Japão. Hotei é apenas um nessa miríade de imagens. Como tornar o estudo da escultura budista japonesa cientificamente viável? Eis que, num primeiro momento, a sistematização do método é tão importante quanto o próprio tema que, por sua vez, não pode perder de vista o objetivo de ampliar a visão de, por enquanto e por preferência, apenas uma cultura, a do Japão.

A sistematização pode começar pela reestruturação da apresentação das imagens, que ainda não pode seguir o mesmo padrão apresentado nos livros japoneses acerca do assunto. O tema ainda é academicamente novo no Brasil, embora o budismo esteja mais disseminado. De qualquer modo, nossa sociedade não se desenvolveu tendo como cenário o budismo e uma grande quantidade de templos e esculturas budistas, como a sociedade japonesa que assim esteve por cerca de mil anos, tempo suficiente para expor o assunto com naturalidade, ou mesmo para fazer uma descrição crítica e comparativa de inúmeros exemplos.

A maior parte dos autores têm seguido em geral três padrões metodológicos de se abordar o tema, conforme se mostra a seguir:

$\mathrm{O}$ primeiro baseia-se em pesquisar as imagens produzidas segundo os ensinamentos do budismo. Essa arte expressa: a sua fusão com o xintoísmo; o paraíso

identificação com as divindades por meio de uma classe especial de meditação. O tantrismo é anti-estético e anti-especulativo. (...). Sua iconografia é apenas um suporte para a meditação, como os mantras, um trajeto mental através da imaginação realizado por uma pessoa em meditação. Embora sem significado para o não-iniciado, são de profundos significados místicos para a iniciação." SAUNDERS, E. Dale. Buddhism in Japan. With an Outline of its Origins in India ("Budismo no Japão. Com um Sumário de Sua Origem na Índia”) Tôkyô: Charles E. Tuttle Company, 1. ed. 1972. p. 78-9.

2. Os Vedas são uma obra composta de quatro livros, complilados em cerca do ano 3100 a. C., e trata de lendas e mitos do povo hindu. O Upanishada é considerado o quinto livro d'Os Vedas.

3. Quando o budismo foi introduzido na China, já atuavam o taoísmo ou confucionismo, que foram fundados respectivamente por Lao-Tsé (570 490 a.C.) e por Kung Fu Tse (Confúcio) (551 479 a.C.). 
e o inferno budistas; crenças específicas em divindade budistas, que se tornaram tão importantes quanto Buda, por exemplo, a crença em Kannon, uma divindade bosatsu.

$\mathrm{O}$ segundo fundamenta-se em pesquisar as imagens de um período histórico ou cultural do Japão. Por exemplo, no período Asuka, do ano 552 a 645, quando um budismo milenar entrou no Japão.

$\mathrm{O}$ terceiro demora-se em pesquisar as imagens de um determinado templo mais famoso ou considerado mais importante. Como um catálogo de museu, apenas as obras do local são apresentadas com uma data aproximada, possível autor, técnicas empregadas e estilo dominante.

Essas abordagens parecem solucionar a complexidade básica de que as imagens "caminharam" por vários períodos, templos e crenças. Exceto as imagens mais famosas e com datas mais precisas, não há um consenso nos exemplos dados para caracterizar as obras de um período, templo ou crença. O caráter remoto do budismo e a grande quantidade, a destruição, a reconstrução e o deslocamento de imagens e templos tornam a pesquisa naturalmente confusa. Há também uma tendência em usar termos do campo artístico como abstracionismo, realismo e naturalismo para levantar questões puramente estéticas, fugindo um pouco da descrição iconográfica.

A descrição apenas iconográfica, sem levar em conta o valor estético, pode, inicialmente, apresentar as imagens budistas e dar uma idéia geral das características que as individualizam. Só a descrição inclui vestimenta, ornamentos, armas, plantas e animais auxiliares e simbólicos, cores dos corpos e objetos citados, fisionomia, gestos das mãos e do corpo em geral, penteado e sobretudo as marcas ou o tipo físico, pedestal, halo, matéria-prima, técnicas e dimensão. A descrição racionalista acadêmica parece não ter relação com a arte oriental. Os elementos iconográficos são amplamente discutíveis pela sua simbologia mitológica. Além disso, estariam essas individualidades simbólicas relacionadas com um realismo? Embora os exemplos de realismo na escultura budista sejam citados com parcimônia, a aplicação dessas teorias sobre a arte oriental é, em parte, ignorar a sua rica iconografia. Por outro lado, trata-se de arte, não obstante religiosa, testemunhos na inata sensibilidade humana.

Segundo a primeira abordagem proposta, os autores japoneses, em geral, no tocante à história da escultura budista japonesa dividem os estilos em cinco períodos iniciais básicos mais ou menos determinados antes da Era Medieval Japonesa: Asuka (552 645), Hakuhô (645 710), Tenpyô (710 794), Jôgan (859 877) e Fujiwara (897 1185). Essa divisão se deve às características essenciais, simples de serem visualizadas e comparadas com o período anterior ou posterior.

O budismo não dominava por completo a sensibilidade artística japonesa, e um fato crucial foi a fusão oficial ou natural do budismo com o xintoísmo. Essa idéia não se limitou apenas à representação de deuses do xintoísmo (os Kami, 神) com aparência de monges budistas. O xintoísmo é parecido com o hinduísmo no seu nativismo, ou seja, ambos surgiram a partir de crenças populares ancestrais e possuem milhares de deuses. A diferença entre os dois está na representação escultural 
antropomórfica. O xintoísmo não teve interesse ou talvez tempo de se desenvolver iconograficamente ao lado da escrita. As imagens pré-históricas do Japão chamadas de dogî (土偶) e haniwa ${ }^{4}$ (埴輪) foram um princípio de estatuária religiosa e suas características são notáveis e enigmáticas. Com a introdução das imagens budistas, aquelas foram esquecidas. Provavelmente foi um choque para a maioria dos clãs a chegada das imagens budistas, pois não havia como competir com a qualidade e quantidade das imagens e com a sistematização literária do budismo (os sutras) com cerca de mil anos de desenvolvimento (a partir de Gautama, sem contar o tempo de existência da crença em budas antes de Gautama). De fato, a escultura religiosa japonesa deu um salto e se tornou japonesa a tal ponto que as imagens budistas parecem ter sido inventadas no Japão, mas isso não significa que tenha havido uma mudança drástica na crença. Muitos budas e deuses do continente asiático foram incorporados ao budismo, tendo sido apreciados como se fossem autenticamente japoneses e assim adorados. Portanto, não se pode falar de uma vitória do budismo sobre o xintoísmo, mas com o xintoísmo e pela arte. Isso pareceu mais adequado às crenças nativas japonesas, às quais muitos deuses hindus e até o próprio Buda foram associados.

A qualidade das imagens budistas que foram produzidas no Japão não se resume ao esforço técnico e aos materiais utilizados. Elas já continham uma grande quantidade de símbolos esotéricos. Pelas escrituras ou apenas pela observação, os escultores tentaram imitar as obras mais antigas com maior ou menor compreensão, ou seja, aquela simbologia foi interpretada pela concepção religiosa japonesa e assim sedimentada pelos séculos.

Uma nova preocupação e solução trazida pelo budismo foi a sua filosofia do destino da alma após a morte. As almas que não estavam preparadas para entrar no paraíso budista nem tinham propensão para ser um kami, certamente iam para os muitos infernos. Se uma pessoa não conseguisse renascer em uma das quatro regiões búdicas, sua alma transmigraria de um para outro de seis mundos inferiores, entre eles o mundo humano. Esses dez mundos são conhecidos como jippôkai (十法界). Um dos temas da arte budista que se tornou freqüente com a popularização do budismo foi

4. Haniwa eram esculturas feitas ao redor dos morros ou colinas tumulares dos nobres do período Kofun (300 646), quando os grandes clãs se tornaram mais poderosos e tornou-se um costume construir grandes morros para funerais, "colina-túmulo" O mais célebre é a do Imperador Nintoku. Os haniwa são ornamentos de terracota (argila modelada e cozida à forno). Primeiramente, eram apenas cilindros de barro e mais tarde foram decorados ou feitos para representar animais, casas, mobílias e utensílios, mas a grande maioria das figuras é de formas humanas e animais. Diferente dos chineses que enterravam figuras semelhantes nas suas sepulturas, no Japão, as figuras não estão enterradas, mas arranjadas ao redor dos montes. Os japoneses também não usavam moldes para facilitar a reprodução como os chineses. As figuras eram feitas manualmente, sem uma preocupação em detalhes, porque foram feitas para ficarem a céu aberto e serem vistas ao longe. Como as figuras de barro anteriores, dogû, era uma atividade artística muito ampla, pois o barro era abundante e sua técnica descomplicada. Há diferentes visões sobre a origem e propósito dos últimos haniwa. O Nihon Shoki ("Crônicas do Japão" 720) diz que eles foram feitos para abolir a prática desumana da auto-imolação com a morte. Podem ter sido desenvolvidos a partir dos postes que cercavam os cemitérios, aos quais foram adicionadas características humanas. No século VI essas imagens foram oficialmente proibidas, mas sua primitividade, em motivo e técnica e vivacidade. embora ofuscada pela introdução da escultura budista do continente, já deixava antever o grande interesse pela estatuária. 
o Nirvana de Shaka, sua libertação do ciclo das reencarnações.

Dentro das proporções desse artigo, deter-me-ei na análise de uma escultura que apresenta Sakyamuni (em japonês, Shaka, 䣋迦), e outras personagens com características diferentes, o que nos ajuda a entender a reflexão de Kato Shuichi sobre o realismo na escultura budista japonesa: “(...) o estilo da escultura budista foi mudando a partir do período Asuka de modos diferentes de acordo com a hierarquia iconográfica. O deslocamento da técnica do abstrato ao representacional foi mais ou menos comum em todos os níveis. $\mathrm{O}$ desenvolvimento do universal ao particular foi notável em relação aos budas, enquanto a particularização da expressão caracterizou os níveis mais inferiores, entretanto, sem chegar à individualidade." 5

A escultura é um tableau ou "quadro de esculturas de barro" que apresenta Buda em seu leito de morte, cercado por seus discípulos e algumas divindades. Segundo as escrituras budistas, quando Buda percebeu que estava perto de entrar no Nirvana, pediu aos discípulos para fazer uma cama em um bosque do lado de fora do castelo de Kusinagara, um reino na Índia Central. Ele se deitou sobre seu lado direito, cabeça para o Norte, face para o Oeste, deu o seu último sermão e entrou no Nirvana.

A imagem de Jivaka, um discípulo de Buda e médico renomado, está segurando a mão direita de seu mestre.

Supõe-se ser uma obra do final do período Hakuhô (645 710) e pertence ao Pagode do templo Hôryûji (Nara, Japão). Esse "quadro" faz parte de um conjunto de esculturas do lado interno dos muros dos cinco andares do pagode onde há outras cenas da vida de Buda. Essa representação do Nirvana, a mais velha existente no Japão, tem sido designada como um tesouro nacional em reconhecimento a seu valor artístico e histórico.

A imagem de Buda é grande, tem 98 centímetros e é dourada, em comparação a outras imagens, de trinta a cinqüenta centímetros e sem cor. $O$ interior da "caverna-quadro" foi uma vez colorido, mas hoje está esbranquiçado por causa do descoloramento, o que aumenta o pesar da cena. Segundo documentos históricos e escavações arqueológicas, era comum a prática de se acomodar, nos vãos dos pagodes, modelos de barro de imagens budistas dentro de uma caverna rugosa.

5. KATO, Shuichi. Style in Buddhist Sculpture. In: Form, Style, Tradition: Reflections on Japanese art and Society ("Forma, Estilo, Tradição: Reflexões sobre a Arte e a Sociedade Japonesa"). Trad. John Bester. Tôkyô/New York e San Francisco: Kodansha International, 1971, p. 126. Grifo meu. 


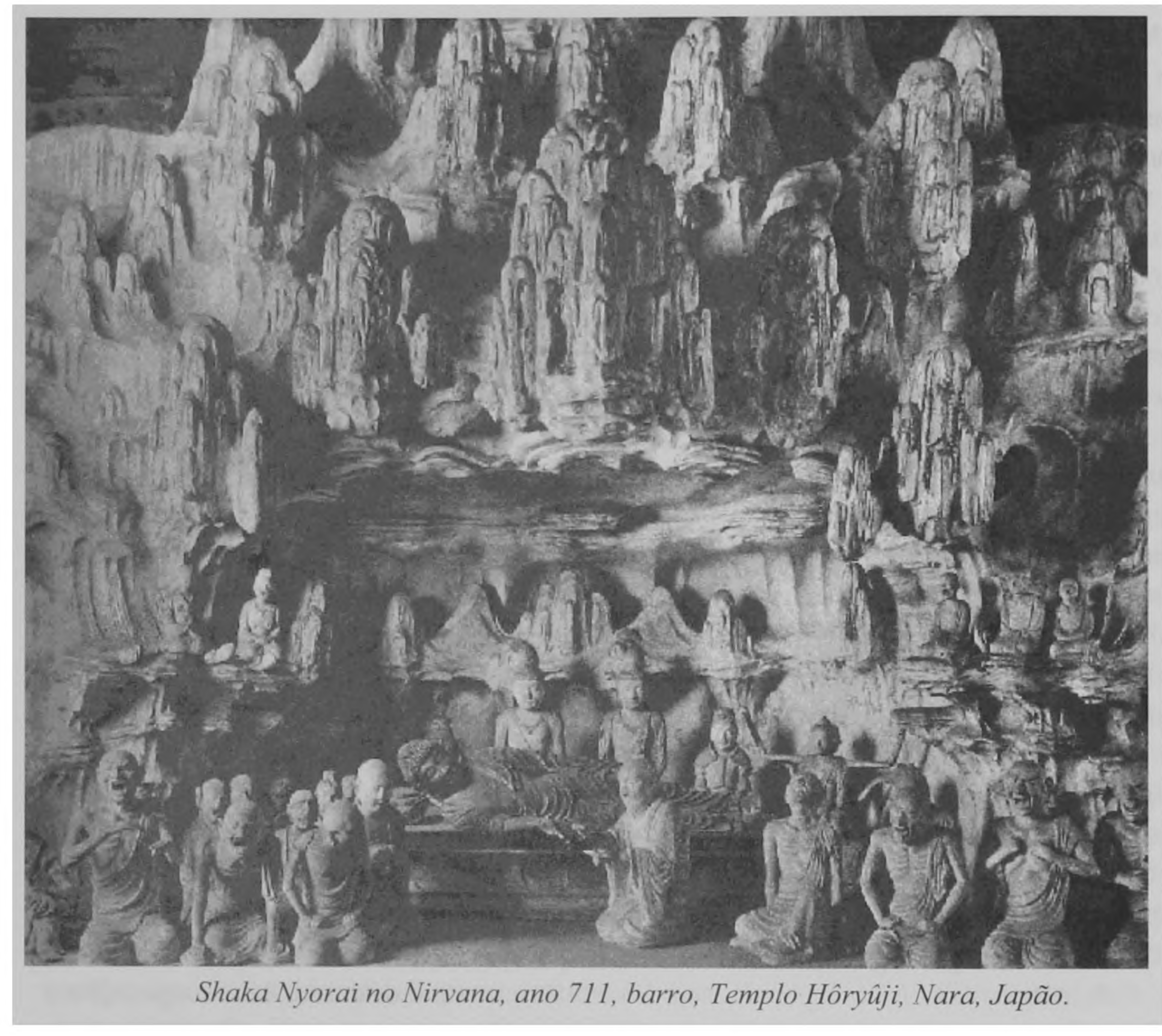

Há três categorias de seres na cena: o ser iluminado Buda, os deuses budistas não iluminados e os discípulos humanos, numa escala decrescente de hierarquia iconográfica baseada na "santidade" Nesse mesmo sentido, o grau de realismo parece crescente.

Há um denominado realismo desse período muito comentado pelos estudiosos com diferentes exemplos que nem sempre coincidem. No que diz respeito à representação de detalhes, deveu-se muito às técnicas de modelagem do barro sobre uma armação de cordas, como a cena citada. Os materiais mais usados foram madeira, barro, terracota, laca e metal (bronze e cobre). O barro “(...) permitiu ao escultor modelar a imagem ao invés de esculpi-la, conferindo uma liberdade de criatividade porque a modificação é possível durante a produção". "Porém, isso é uma discussão complexa, pois não pode ser dissociada da hierarquia das imagens budistas. Através da relação entre as obras e os materiais podemos supor uma concepção de realismo.

$\mathrm{O}$ realismo tem, em algum grau, uma relação com detalhes. Portanto, a

6. MIZUNO, Seichi. Asuka Buddhist Art: Hôryûji (“Arte Budista de Asuka: Hôryûji”). Trad. Richard L. Gage, New York, Weatherhill - Visão da Arte Japonesa / Tôkyô: Heibonsha, 1974. v. 4. 
estatuação fiel do objeto retratado, no caso, uma forma humana, com detalhes físicos que podem tender para uma expressão das proporções ideais de beleza universal, como as estátuas de deuses da Grécia Clássica, ou a expressão de uma emoção particular num momento particular, que possa ser reconhecida por qualquer cultura.

No início, pensava-se que Buda, por ser um homem santo, não podia ser retratado, mesmo porque sua imagem já era, em si mesma, envolta em idealização. Só se faziam esculturas de seu pé com os sinais de sua grandeza espiritual. Quando imagens de corpo inteiro surgiram, tinham características próprias de um buda. Muitas delas não puderam ser representadas na escultura, como "um hálito perfumado" mas outras, que podem ser vistas nessa imagem, mostram uma protuberância no topo da cabeça e cabelos encaracolados. Acredita-se que essas características foram de um rei da mitologia hindu, e já eram aparentes nas imagens budistas de Gandhara.

Além dos fatos empíricos, as lendas também contribuem para explicar as imagens. Esse realismo tem relação com a realidade das lendas e dos mitos do complexo universo budista. Como Jesus Cristo, seu retrato pode ter sofrido muitas idealizações segundo interesses por vezes preconceituosos, já que ninguém pode provar a favor ou não. Gautama e Jesus são temas de expressões artísticas que tendem a uma certa universalização, que nem sempre ultrapassam características étnicas. Nesse caso, o realismo é um ponto de vista de uma crença. Dizer que Gautama não era japonês tem uma importância científica e não deve significar um sacrilégio artístico ou religioso. Podemos também dizer que ele é muito mais japonês devido a seu profundo enraizamento nessa etnia e porque muito do budismo no Brasil chegou através dos imigrantes japoneses, chineses e coreanos.

Para fechar essa discussão sobre a imagem de Buda, vemos que revestir sua imagem com folhas de ouro ou bronze dourado é uma das características principais, afinal, Buda é um ser "com luz própria" ou seja, "iluminado pela sua sabedoria" $\mathrm{O}$ halo, normalmente presente nas imagens budistas, não está presente, mas está implícito na cor dourada da pele e do manto. O crente tem a sensação de estar ao lado de um "super-humano" Enquanto escultura, o manto é esculpido ao mesmo tempo em que se idealiza o corpo que está abaixo e sua idealização é um dos pontos em que mais se discutem estilo e técnica, do abstrato ao representativo. $O$ manto de Buda neste quadro, aparece bem abstrato. O manto sugere fluidez de "uma fonte de serena sabedoria", emprestando uma aparência líquida à solidez do material. Há uma

7. Foi na região de Gandhara, parte superior do Rio Indo, que a iconografia de um homem santo em formas reconhecíveis, gradualmente foi tomando forma, fazendo surgir a imagem antropomórfica de Buda. A região de Gandhara tinha sido por longo tempo um cruzamento de numerosas influências e gregos já habitavam por lá por muito tempo levando a civilização helenística. Durante o reinado de Ashoka (ca 296 232 a. C.), a região tinha se tornado cenário de intensiva atividade de missionários budistas. As primeiras imagens de buda no sudeste asiático apareceram por volta do século I, em esculturas e monumentos, mostrando as influências das etnias locais. No século I d. C., os governos do império Kushan, que incluia Gandhara, mantiveram contato com Roma e pode ser que então começaram a surgir as primeiras imagens budistas semelhantes a deuses gregos. 
composição equilibrada dos estados sólido, líquido e gasoso representados respectivamente pelo corpo, manto e halo.

A influência da arte indiana de Gupta $^{8}$ também sugere um prazer sensual. Se vista sob a dualidade ocidental, essa sensualidade pode ser interpretada como um naturalismo quase obsceno. Assim como o uso da palavra realismo, não podemos pensar num Buda obsceno quando o seu manto diáfano revela, por baixo, o seu peito ou quando ele aparece sem o manto, independentemente das crenças pessoais. Uma das características das imagens de um buda é obliterar o pênis. Buda estaria além da sexualidade, mas não da sensualidade.

Num segundo nível mais baixo temos as imagens de deuses budistas. Uma delas é Ashura. Os Ashura são semi-deuses, uma interpretação da deusa hindu Kali, mas com algum jeito de titã grego. Foi originalmente um demônio que obstruiu a expansão do budismo. Chegou ao Japão no século VI. Sua onipotência é simbolizada por suas três faces que expressam um aspecto de guerreiro ameaçador e seis longos e graciosos braços simbolizando numerosas atividades. A partir de Ashura, outras divindades budistas também terão mais que dois braços, concentrando os diversos pedidos dos adoradores. As Kannon Bosatsu, Fukûkenjaku Kannon de seis braços e Senju Kannon de "mil mãos" são outros exemplos.

Os Ashura fazem parte das Vinte e Oito Legiões, guardiões originários da mitologia hindu que foram incorporados ao budismo. Eles estavam presentes quando Buda expôs seus ensinamentos e ouvindo-o, converteram-se e tornaram-se seus seguidores. Os Ashura e os Deuses Celestiais representam os dois mais altos estados de existência antes do "estado de buda"

Atrás de Buda há três divindades que também estão nesse segundo nível. Os dois da esquerda provavelmente são dois Bosatsu e o terceiro um Deus Celestial.

Miroku, como foi dito, é um bosatsu. Bodhisattva, em sânscrito, (em japonês, bosatsu, 菩薩,) é um ser iluminado ou santo que jurou adiar o seu nirvana até que todos os seres conscientes conseguissem alcançar a salvação. É como Gautama quando ele ainda era um príncipe, usando hábito e ornamentos de um príncipe indiano. Portanto, todo buda já foi um bosatsu. Normalmente são jovens e esbeltos, com uma expressão compassiva, sem traços fisionômicos que demonstrem perturbação mental. Os cabelos ficam arranjados no topo da cabeça, normalmente amarrados em um topete ou coque e usam uma coroa. Há muitos bosatsu. No Japão, na China e no Tibete, monges altamente reverenciados são freqüentemente elevados ao estado de bodhisattva durante sua vida ou após a morte. No Tibete, Dalai Lama, por exemplo, é considerado ser a reencarnação do bodhisattva Kannon.

\footnotetext{
8. As tradições de Gandhara foram posteriormente expandidas para o Afeganistão e através da Ásia Central como Arte Kushan e a arte de Mathura eventualmente deu nascimento à Arte Gupta, de corpos cheios e veste diáfana. Durante a dinastia indiana Gupta (320 510), a pintura e a escultura budista demonstravam estabilidade, elegância e serenidade. Os Guptas cresceram em Magadha e estabeleceram um grande reino sobre grande parte do norte da Índia. Esse período é também conhecido como a Era Clássica ou Era de Ouro da antiga Índia.
} 
Foi dito que Hotei faz parte da categoria de deuses celestiais chamados Ten. Embora esses deuses vivam anos incontáveis, ainda estão presos ao ciclo das reencarnações. Eles ouviram e acreditaram nos ensinamentos de Buda e prometeram defender o budismo. Assim com os bosatsu, grupos particulares de devas são afiliados com budas particulares e bosatsu para formar grupos iconográficos distintos, pois são seus guardiões. Os devas foram muito proeminentes durante o período Heian (794 1185). Eles têm sexo distinto e os masculinos são retratados na forma de monarcas musculosos usando armaduras. Os Quatros Nobres Guardiões Celestiais (Shi Ten, mais conhecido como Shitennô 四天王) são os exemplos mais citados. A solidez de seus corpos tridimensionais suporta características de fúria e compaixão de forma equilibrada.

O terceiro nível tem relação com a realidade da impermanência, pois se trata de seres humanos mortais bem definidos por Conze ${ }^{9}$ em se referindo aos Dez Mundos de transmigração da alma: "O nascimento na forma humana é essencial para a apreciação do Dharma (Leis Budistas). Os deuses são felizes demais para sentir desgosto pelas coisas condicionadas e vivem demasiado tempo para apreciar a impermanência. Os animais, os fantasmas e os condenados não têm clareza de pensamento"

Os discípulos chorando em primeiro plano demonstram com seus corpos, e não só na expressão facial, um tipo de emoção restrita e humana, especificamente, o de muita dor e pesar, sob a particular circunstância da morte de Buda. O olhar fixo, mãos nos joelhos ou peito, os músculos e as pregas de seus mantos são representados realisticamente. Porém, não demonstram individualidade no sentido de que diferem um do outro, embora os discípulos tenham sido indivíduos diferentes. Há uma preocupação maior com a expressão de sentimentos universais, o que não torna as duas categorias anteriores menos realistas em suas respectivas mitologias. Entretanto, hierarquias diferentes colocadas juntas possibilitam uma interpretação de um mesmo fato em formas artísticas diferentes, assim como as três escritas egípcias na pedra de Roseta. Todos estão vivendo um mesmo momento particular e vivenciando as mesmas emoções conforme as suas naturezas. Buda está com uma expressão de paz sublime. Ashura e Devas já viram muitos budas passarem pela terra e os discípulos mergulham em questões existenciais.

Os escultores budistas japoneses exploraram o realismo e a possibilidade de representar todos os seres do universo budista em formas antropomórficas com um estilo próprio. O Período Tenpyô (710 794) é considerado o período clássico da escultura budista japonesa por causa do refinamento das características corporais das imagens em busca de formas mais atraentes: uma postura mais livre, perfil mais cheio, com bochechas mais cheias e faces mais maduras, lábios mais realistas, olhos estreitos pintados com curvas mais delicadas e mãos mais carnudas e robustas. A

9. CONZE, Edward. El Budismo, su esencia y su desarrollo. México. (Breviarios 275 del Fondo de Cultura Económica), 1978. Original: CASSIER, Bruno. Buddhism. Its essence and development. Inglaterra: Oxford, 1951, p. 69. 
exploração da tridimensionalidade, o material e a textura lhes permitiram alcançar um maior detalhamento.

A concepção japonesa foi expressiva no sentido de suscitar apelo emocional, uma tendência esotérica, e rever as esculturas chinesas. Esses novos traços foram uma expressão direta dos sentimentos japoneses inteiramente projetados sobre os deuses budistas, de como deveriam ser em sua aparência. Nessa criação, houve uma certa liberação da criatividade, dentro dos limites iconográficos, pois a imagem de buda não é uma forma humana. Isso parece ter sido importante para os escultores, pois eles concentraram os seus esforços para expressar o ideal de santidade tão acuradamente quanto possível, já que não era possível retratar a forma realística de Buda e de outras imagens budistas com três olhos e oito braços.

Se considerarmos que as imagens budistas não podem se estudadas enquanto elemento cultural japonês, visto que o budismo e sua escultura não nasceram no Japão, isso seria o mesmo que dizer que não há escultura budista japonesa ou que se há, não tem valor algum, que não existe budismo japonês ou bibliografia a respeito. Por outro lado, a qualidade e a quantidade de imagens budistas produzidas no Japão revelam muito da arte e da crença japonesa, acumulando significados de uma arte autenticamente oriental.

\section{Bibliografia consultada}

CONZE, Edward. El Budismo, su esencia y su desarrollo. México. (Breviarios 275 del Fondo de Cultura Económica), 1978. Original: CASSIER, Bruno. Buddhism. Its essence and development. Inglaterra: Oxford, 1951.

Hayakawa, Monta. Explanation of the cover illustration. Japan Review. Kyôto: Bulletin of International Research Center for Japanese Studies, Nichibunken. v. 1, n. 224, 1990 e v. 7, n. 199, 1996.

Kato, Shuichi. Style in Buddhist Sculpture. In: Form, Style, Tradition: Reflections on Japanese art and Society ("Forma, Estilo, Tradição: Reflexões sobre a Arte e a Sociedade Japonesa"). Trad. John Bester. Tôkyô/New York e San Francisco: Kodansha International, 1971. p. 59 126.

Mizuno, Seichi. Asuka Buddhist Art: Hôryûji ("Arte Budista de Nara: Hôryûji”). Trad. Richard L. Gage, New York, Weatherhill - Visão da Arte Japonesa / Tôkyô: Heibonsha, 1974. v. 4.

TAKASHI, Ishikawa. "The Masterpieces of Hôryû-ji Temple" ("As Obras-Primas do Templo Hôryû-ji”). The East, v. 22, n. 5, Tôkyô, setembro, 1986, p. 8-13. 